\title{
EL ESTRATO PATRIMONIAL EN LA IDENTIFICACIÓN VISUAL DEL ESTUARIO DEL GUADALQUIVIR
}

\author{
JOSÉ RAMÓN BARROS CANEDA \\ joseramon.barros@uca.es \\ UNIVERSIDAD DE CÁDIZ \\ http://dx.doi.org/10.25267/Riparia_sup.2018.11.11
}

Los diferentes factores económicos, sociales, políticos y en consecuencia culturales que definen a lo largo del tiempo la construcción histórica de los territorios depositan sobre ellos una serie de elementos de naturaleza material e inmaterial que se van convirtiendo en huellas de esa secuencia. Si importantes son dichos elementos desde el punto de vista del documento histórico, no menos lo son como generadores y portadores visuales de sus señas de identidad. La percepción desde el presente de esos hitos depositados en estratos históricos sobre el territorio (Georgescu, 2015, p. 20), genera una nueva capa, un nuevo "metaestrato" sincrónico o sintagmático en el que queda contenido de forma horizontal todo el proceso acumulativo, suministrando un potente sistema de identificación visual que condiciona la gestión y progresión del territorio, el paisaje y los ámbitos urbanos.

Planteada esta hipótesis, trataremos de ver su aplicación en el ámbito territorial del Estuario del Río Guadalquivir, reflexionando sobre los hitos que afloran en el paisaje para articularlos, jerarquizarlos y así entender su integración en el actual escenario de la desembocadura ${ }^{1}$.

\section{Historia y territorio}

Antes que nada, resulta imprescindible definir el marco geográfico en el que se insertan dichos elementos, un territorio, como veremos, de gran relevancia cultural y cohesionado directa e indirectamente por la presencia del río. Un territorio que, en su devenir histórico, ha gestado tres puntos de referencia claros en los que han crecido otros tantos núcleos urbanos que aúnan buena parte de la identidad cultural de la zona. La zona sur, costera, aglutinada por la Bahía de Cádiz, con la ciudad de Cádiz como centro del comercio con América durante el siglo XVIII; más al norte el estuario del Guadalquivir con los núcleos urbanos de Sanlúcar de Barrameda y Chipiona, un territorio entre lo marítimo y lo fluvial y más al norte aún, en el curso del río, Sevilla, una ciudad tierra adentro y de vínculos fluviales, cabecera del comercio con América durante los siglos XVI y XVII.

Contextualizado el territorio, sólo una mención a la diversidad tipológica que la legislación patrimonial ha registrado en la zona del estuario con el objetivo de dejar patente la importancia del componente cultural de la zona. Por una parte, la presencia de Patrimonio Natural concentrado en el Parque Nacional de Doñana declarado Patrimonio de la Humanidad en 1994; sin menoscabo de otras zonas bajo el amparo de regímenes jurídicos de ámbito estatal y autonómico, caso de la zona marítimo-terrestre protegida por la Ley de Costas y la legislación nacional sobre Espacios Naturales Protegidos. Por otra, la importantísima acumulación de Patrimonio Cultural Material mueble, inmueble y urbano; así como el dispuesto en los tramos de costa marítima o ribera fluvial. Por último, la incorporación de

\footnotetext{
${ }^{1}$ Estos hitos vienen definidos por los conceptos Patrimonio Cultural y Patrimonio Natural, figuras convencionales que la legislación histórica nacional e internacional sobre Patrimonio ha adoptado para proteger jurídicamente, concepto éste también convencional, elementos considerados relevantes.
} 
Patrimonio Cultural Inmaterial representado por la Romería del Rocío que se celebra en la ciudad de Almonte, provincia de Huelva, y uno de cuyos itinerarios atraviesa el río por la ciudad de Sanlúcar. Este patrimonio, no protegido jurídicamente, se encuentra en cambio registrado y documentado en la Base de Datos del Patrimonio Inmaterial de la Comunidad Autónoma de Andalucía.

Serán, sin embargo, los núcleos urbanos del estuario, Sanlúcar y Chipiona, los mayores aglutinadores del complejo y variado patrimonio cultural material, generado a través de una serie de factores que lo ha ido determinando y que, aliados y en secuencia histórica, han producido todo un conjunto de hitos y huellas que vienen a dar cuerpo a este proceso de identidad visual del estuario. Estos factores vienen definidos por la configuración física del territorio; el proceso histórico de ocupación y la presencia de modelos urbanos históricos asociados a regímenes económicos.

Así, la configuración del territorio viene dada por la presencia del mar y su línea de costa, y el río y sus dos riberas. Este espacio marítimo-fluvial configuró un parámetro geográfico vital para el crecimiento de Sanlúcar de Barrameda, principal núcleo urbano del entorno. La navegación por el río de la flota durante los siglos XVI y XVII camino de Sevilla, cabecera entones del comercio con América, representó un impacto económico crucial para el desarrollo de la ciudad y de su entorno. Por otro lado, la zona terrestre configurada en Sanlúcar de Barrameda por la ribera izquierda del río y por una elevación conocida como la Barranca, que se convirtió en espacio defensivo natural y desde el cual fue creciendo la trama urbana. A través de estos dos accidentes geográficos se fue articulando el solar de la ciudad en dos espacios perfectamente delimitados que luego serían conocidos como el Barrio Alto y el Barrio Bajo.

Este formato territorial y orográfico sumado al acontecer histórico favoreció un proceso de ocupación cuyos hitos principales desde la Edad Media a la actualidad pueden resumirse en:

- La construcción de la Villa Señorial al serle entregada por el rey Fernando IV en 1297 a Guzmán el Bueno como recompensa por su participación en la expulsión de los musulmanes ${ }^{2}$. Y en esta línea, la posterior generación del Ducado de Medina Sidonia cuya cabecera fue finalmente Sanlúcar, lo que favoreció el crecimiento de la ciudad hacia la ribera del río en lo que posteriormente se denominó Barrio Bajo (Véase Laredo, 2011).

- El proceso histórico de colonización y comercio con América durante los siglos XV, XVI y XVII, que convirtió a Sanlúcar en punto de referencia para la flota. De esta ciudad partieron expediciones muy relevantes como el tercer viaje de Cristóbal Colón en 1498 o la de Magallanes y Elcano que dio lugar a la primera circunnavegación del mundo en 1519. A esto hay que sumar la creación, en Sevilla en 1503, de la Casa de la Contratación, organismo que regulaba y dirigía todo el comercio con América y que supuso el impulso definitivo a Sanlúcar como puerto y puerta de acceso a la navegación fluvial hacia Sevilla.

- La decadencia económica durante el siglo XVIII, debido al desplazamiento del centro del comercio con América a Cádiz. Debido al aumento del calado de los barcos, comenzó a resultar difícil y poco rentable la navegación hacia Sevilla lo cual

${ }^{2}$ El proceso histórico de la zona es, es evidentemente anterior, e incluso existen huellas de la etapa romana y musulmana (Véase Parodi,2011), pero nuestra hipótesis basada en la configuración de la identidad visual a través del patrimonio cultural sólo puede contar con estructuras que permanecen y que forman parte del perfil de la ciudad. 
condujo finalmente al traslado de la Casa de la Contratación en 1707 a la costera ciudad de Cádiz. Este hecho, que impulsó el despegue político y cultural de la bahía gaditana, supuso, en cambio, un considerable declive para para la zona de Sanlúcar.

- El proceso de industrialización del XIX en base a la vitivinicultura y al inicio del turismo como valor económico y de ocupación del territorio, factores que se mantienen hasta la actualidad.

- Relacionado con la expansión del concepto Patrimonio Histórico-Artístico en las décadas de 1980 y 1990 y su denominada "sostenibilidad turística", podemos hablar de la Patrimonialización como factor histórico que interviene, por un lado, como un potente condicionante que genera fricciones en la evolución y gestión de la ciudad contemporánea y por otro como conservador de los valores de identidad visual y cultural.

\section{Los modelos de ciudad}

Este conjunto de factores territoriales e históricos generaron modelos de ciudad que se fueron depositando como capas, en ocasiones solapadas, sobre la planta urbana. A través de una serie, fundamentalmente, de inmuebles cuyas tipologías permanecen vinculadas a los valores de cada etapa, la ciudad se fue poblando de referentes que se convierten en portadores de valores patrimoniales visuales de esta zona del estuario del río.

Podemos citar, con presencia actual, un primer modelo que empieza a desarrollarse en la Edad Media sobre el núcleo histórico de la zona alta de la Barranca. En ese espacio creció un tipo de ciudad defensiva, amurallada al modo alcazaba, muy asociada a los valores políticos y económicos del régimen señorial protagonizado, en este ámbito, por la casa de Medina Sidonia. Este formato incluía el trazado de la muralla -un rectángulo casi perfecto- uno de cuyos lados corría sobre el escarpe de la barranca y que, pese a haber desaparecido, su silueta ha quedado impresa en la actual trama urbana a través del trazado de viario. En el interior del recinto se desarrollaba el modelo habitual de las denominadas villas ducales (Alegre, 2014), que con el tiempo tendió a convertirse en espacio ennoblecido de representación institucional. Este modelo de ciudad incluía, además de la muralla, un conjunto de inmuebles que actuaban como símbolo del poder y con valores defensivos. De ellos, en la actualidad permanecen algunos fragmentos de la muralla incluida la Puerta de Rota como uno de los accesos al recinto, el imponente castillo de Santiago, el palacio ducal, la iglesia ducal y la cilla. Estos valores defensivos se extendían a la ribera del río y a la costa marítima a través de pequeños fuertes como el del Espíritu Santo y El Salvador o torres albarranas defensivas, como la de San Jacinto en la costa atlántica de Doñana.

Un segundo modelo de ciudad será el denominado Ciudad-Convento que se gestó durante los siglos XVI y XVII y que vendrá marcado por la destacada presencia de arquitectura cultural/religiosa. La cronología de este modelo coincide con la expansión de la ciudad fuera de las murallas medievales en su crecimiento hacia la playa de Bajo de Guía y hacia la ribera del río en el Barrio Bajo o Arrabal del Mar. Este modelo, muy extendido en la Edad Moderna española, viene caracterizado por la profusión de extensas parcelas conventuales que suelen actuar de ordenadoras y centralizadoras de zonas amplias de la trama urbana y que nos acercan a un tipo de escenario urbano de calles encajonadas por altos muros ciegos propios de las clausuras. Es el caso, por ejemplo, de los conventos de Santo Domingo y San 
Francisco en la calle Santo Domingo; o Madre de Dios y Regina Coeli alineados a los pies de la barranca ${ }^{3}$.

El tercer modelo se corresponde con la Ciudad Burguesa. La decadencia del comercio con América durante el siglo XVIII, abre la puerta hacía un nuevo modelo definido por la actuación de una burguesía industrial que en consonancia con otras zonas del entorno, caso de Jerez de la Frontera o El Puerto de Santa María y aprovechando la existencia de una economía vitivinícola bastante anterior, desarrolla un modelo de ciudad en la que se asienta la actividad industrial vinculada con el vino. La bodega, como edificio significativo, con su perfil de nave industrial y cubiertas a dos aguas se esparce por la ciudad insertándose y en ocasiones asentándose sobre los modelos históricos precedentes. De hecho, configura un tipo de urbanismo similar al de la ciudad conventual a base de grandes parcelas cerradas por elevados muros con escasos o muy reducidos vanos. Tan próximo resultaba el modelo de ciudad y la tipología de los inmuebles que incluso se adaptaron como bodegas algunos conventos desamortizados.

Este modelo de ciudad trazado desde la burguesía añadirá su paulatina conversión en centro de turismo para la sociedad sevillana que la poblará de hoteles de rasgos historicistas y regionalista como los situados en la actual avenida de Bajo de Guía (Véase Gómez-Díaz, 2011). La playa como atractivo turístico que se inició con la alta burguesía sevillana, atraída por la instalación de la familia real de los Montpensier, continuará como punto de referencia durante el siglo XX, llegando, por ejemplo, a transformar el barrio pesquero de "Bajo Guía" en espacio gastronómico.

Por último, podemos hablar de uno de los modelos que define a la ciudad contemporánea y que hemos denominado la Ciudad Patrimonial. Este estrato viene marcado por la toma de conciencia de la importancia de este recurso cultural "identitario" como actividad económica. El mantenimiento de un patrimonio tan intenso y extenso que junto con la actividad vitivinícola actúa como motor económico, genera una ciudad altamente patrimonializada con las consecuentes ventajas e inconvenientes en cuanto a la gestión de la misma. Al respecto el mapa que acompaña a este texto, organizado por modelos de ciudad, demuestra el alto porcentaje existente de bienes inmuebles con valores patrimoniales ${ }^{4}$, cuyo valor conjunto conforma esa capa que hemos denominado patrimonial. En este estrato contemporáneo se proyecta toda la identidad histórica y parte de la actual economía del entorno del estuario del Guadalquivir, conduciéndola a ese estado de patrimonialización del territorio. Un valor reconocido y activado por la aplicación de una legislación sobre patrimonio desarrollada a nivel estatal, autonómico y local. Es el caso de la Ley de Patrimonio Histórico Español, la Ley de Patrimonio Histórico de Andalucía y el Plan General de Ordenación Urbana con sus catálogos de inmuebles con diferentes niveles de protección jurídica. En la vista aérea que acompaña al texto puede observarse el elevado nivel de bienes inmuebles protegidos, pero además hay que tener en cuenta que existen otros 393 edificios de arquitectura doméstica protegidos también por la legislación. No puede olvidarse tampoco que a estos inmuebles hay que añadir cerca de 1.700 bienes muebles registrados en los catálogos de protección de la administración cultural. Ni tampoco la existencia de cortijos

\footnotetext{
${ }^{3}$ Un total de 23 edificios monumentales de naturaleza religiosa entre conventos y parroquias se ubican en una ciudad con población actual próxima a los 67.000 habitantes (Véase Barros, 2016)

4 Azul: La Ciudad Señorial. Inmuebles asociados a la defensa. Rojo: La Ciudad Convento. Inmuebles religiosos. Verde: La Ciudad Burguesa: Inmuebles de tipología industrial bodeguera. Amarillo: La Ciudad Turística.
} 
históricos con actividad agroprecuaria en el entorno del término municipal: La Cañada, Evora, Cabeza de Alcaide, Miraflores, Monteagudo y Mestre. La suma de todos estos recursos indica el elevadísimo nivel de patrimonialización de una ciudad de las denominadas Ciudades Medias (entre 50.000 y 300.000 habitantes).

A modo de conclusiones podemos afirmar que en torno al estuario se ha producido una intensa y progresiva ocupación histórica de naturaleza urbana concentrada en la margen izquierda. En dicho proceso el Guadalquivir como medio de comunicación navegable y como generador de actividad ha suministrado un soporte permanente para el desarrollo de la zona, hasta el punto de que se erige en referencia para los modelos históricos de ciudad, cuyos valores han ido adaptándose a los ofrecidos por el río, incluso en momentos de decadencia.

Siendo el río por tanto referencia permanente, los hitos arquitectónicos y la disposición de la trama urbana de la ciudad de Sanlúcar, en el presente de elevado valor patrimonial, han construido un potente valor de identificación visual que se traslada, junto con el Parque Nacional de Doñana, al sentido de identidad del paisaje del estuario del Río Guadalquivir, que se inserta como nueva capa histórica en el proceso histórico de la zona.

\section{Bibliografía}

J.R. BARRos CANEDA, «La ciudad desplegada. Forma y espacio en la Sanlúcar del siglo XVI », en M. Parodi Álvarez (coord..), In Medio Orbe. Sanlúcar de Barrameda y la I Vuelta al mundo, Sevilla, 2016.

E. Alegre Carvajal, Las villas ducales como tipología urbana, Madrid, 2014, URL: http://e-spacio.uned.es/fez/eserv/tesisuned:GeoHis-Ealegre/Documento.pdf.

A. GeOrgescu Paquín, La actualización patrimonial a través de la arquitectura contemporánea. Gijón, 2015.

A. Gómez DíAz-FrANZÓN, «La arquitectura del veraneo », en El Río Guadalquivir. Del mar a la marisma. Sanlúcar de Barrameda, II, Madrid, 2011.

M.A. LAdero QueSADA, «Sanlúcar medieval», en El Río Guadalquivir. Del mar a la marisma. Sanlúcar de Barrameda, II, Madrid, 2011.

L. Martínez Montiel, J.R. Barros Caneda y otros, Clausuras. Conventos y monasterios en Cádiæz, Cádiz, 1998.

L. Martínez Montiel, J.R. Barros Caneda y otros, Sanlúcar de Barrameda. Patrimonio Cultural, Cádiz, 2006.

M. J. Parodi Álvarez, «El Guadalquivir puerto de entrada de Civilizaciones », en El Rio Guadalquivir. Del mar a la marisma. Sanlúcar de Barrameda, II, Madrid, 2011.

J.P. VelázQuez GAZTElu, Historia Antigua y Moderna de la muy noble y muy leal ciudad de Sanlúcar de Barrameda, ed. M. Romero Tallafigo, II, Historia Moderna: de la Reconquista al reinado de Don Fernando VI, Sanlúcar de Barrameda, 1994. 


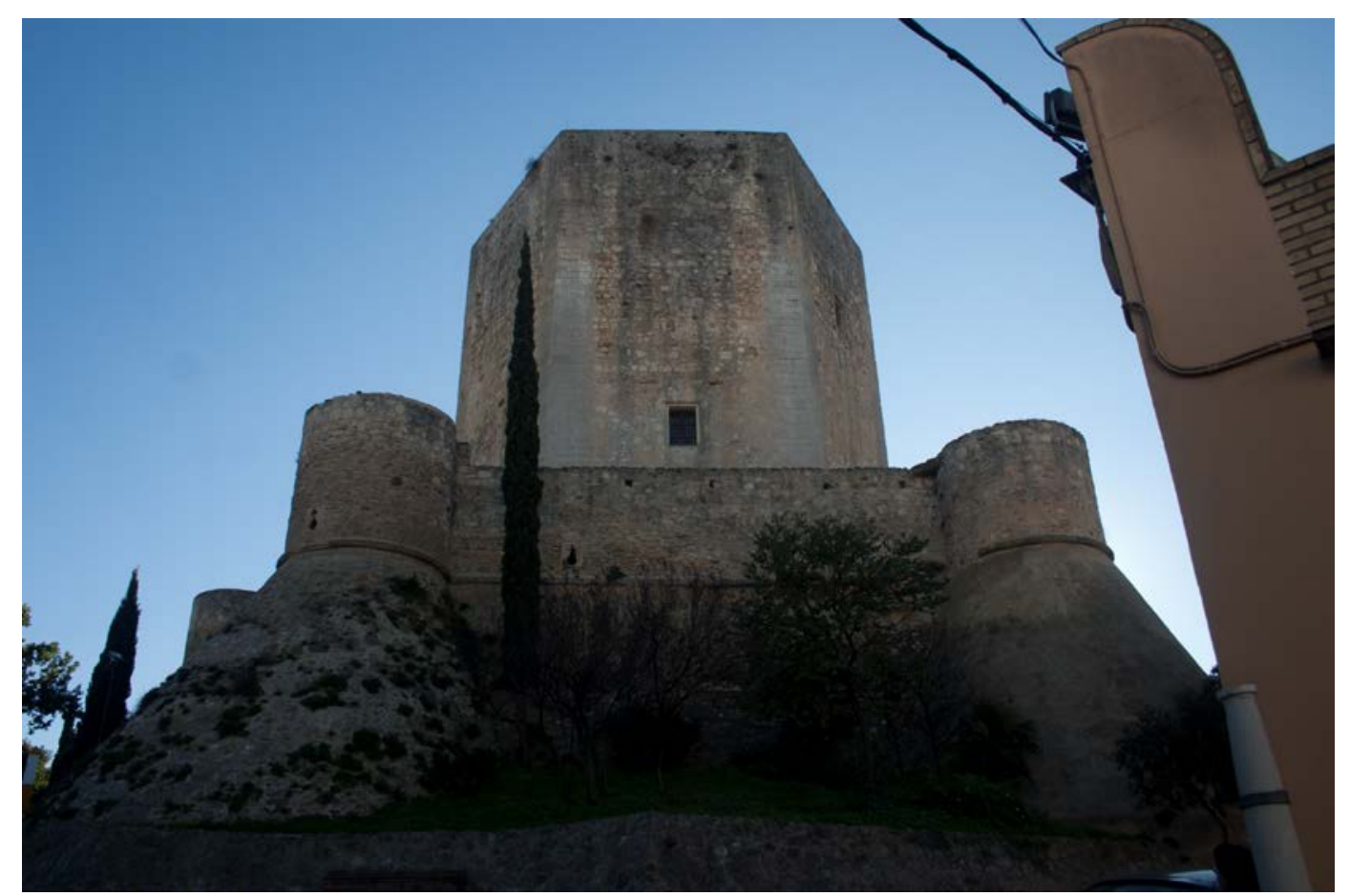

Fig. 1. Vista del castillo de Santiago de Sanlucar de Barrameda. La ciudad defensiva.

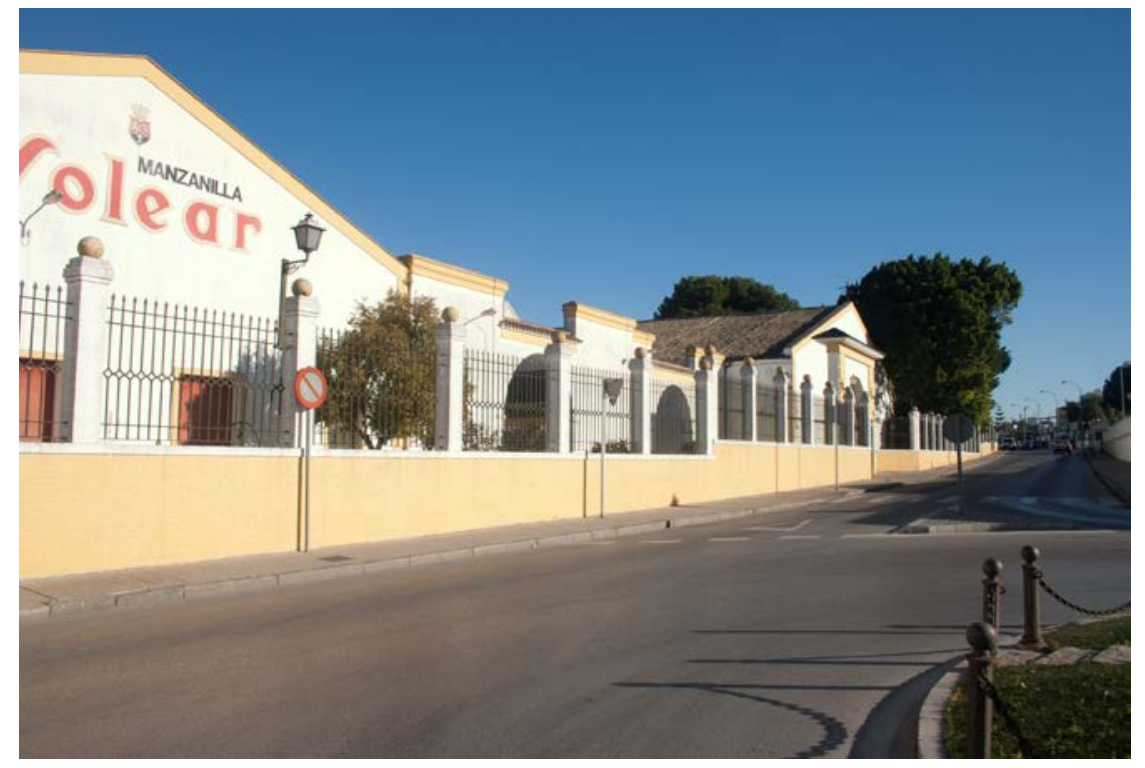

Fig. 2. Vista de las bodegas Barbadillo de Sanlúcar de Barrameda. La ciudad burguesa. 


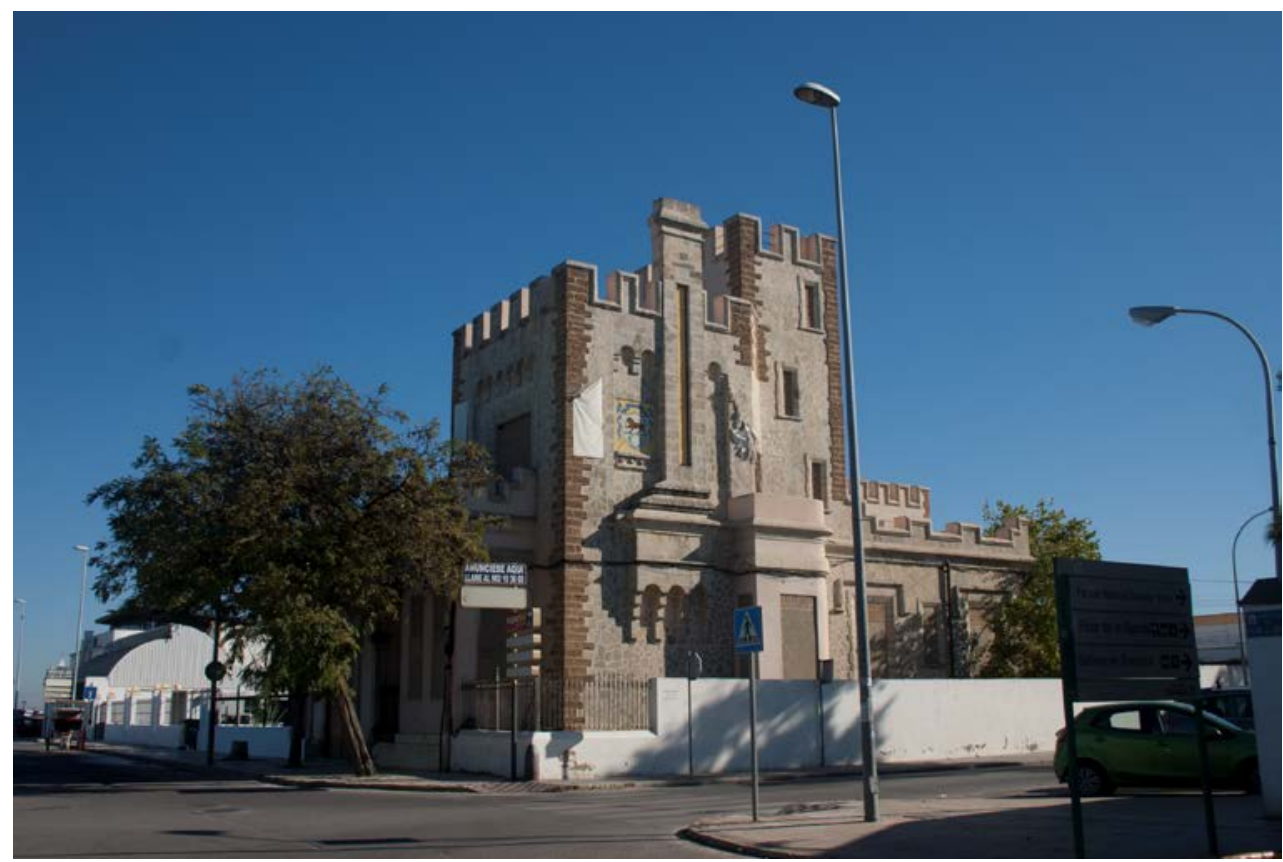

Fig. 3. Vista de un chalet de la Av. Bajo de Guia de Sanlúcar de Barrameda. La ciudad turística.

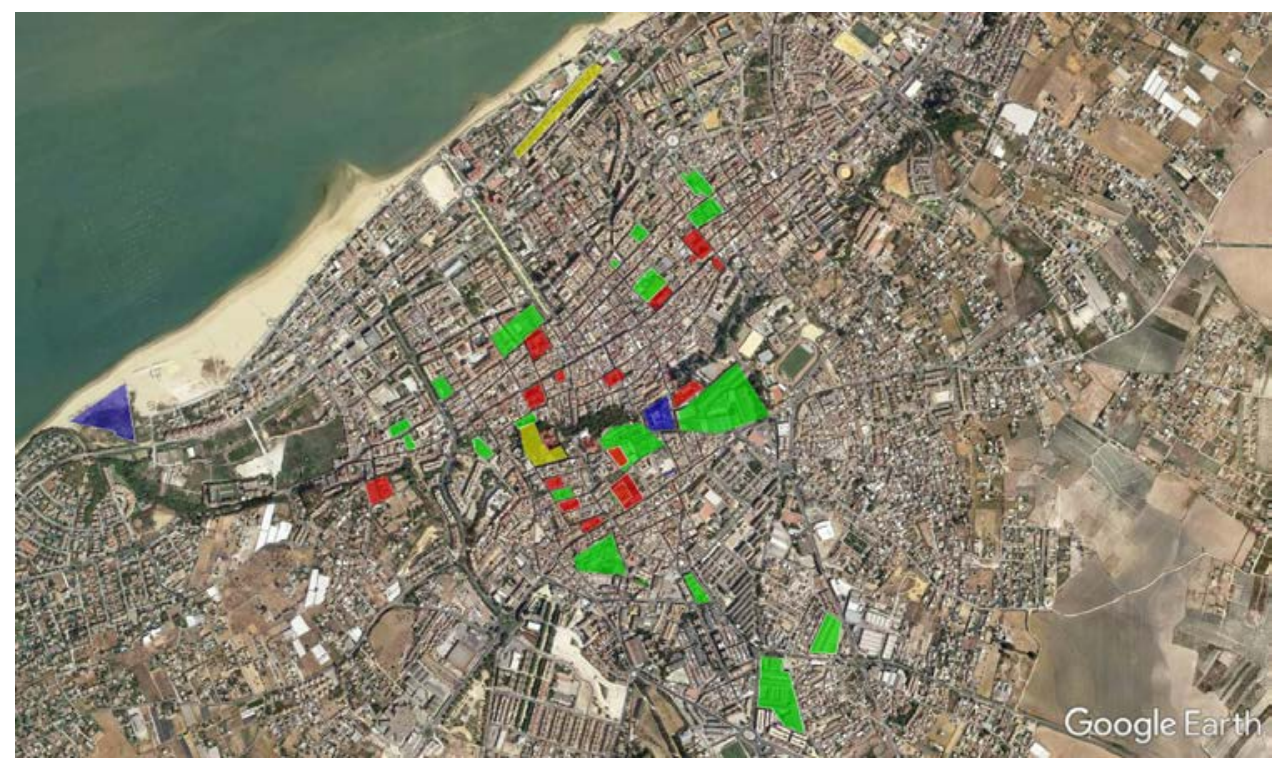

Fig. 4. Inmuebles protegidos de Sanlúcar de Barrameda. Google Earth. Data SIO, NOAA, U.S. Navy, NGA, GEBCO. Image Landsat Copérnicus. 